(a) The colour (orange) is due to pigment in the skin, and not to the red colour of the nervous system; I may mention that Duges' species, "Prostoma clepsinoides," was yellow ochre, and "Pr. lumbricoideum" was yellow marbled with red; whilst Leidy's "Emea rubra" was yellowish flesh-coloured (probably due to the hæmoglobin in the nervous system).

(b) The anterior pair of eye-spots is further from the prostomium than in Silliman's drawing; I found no third pair of eye-spots, which, however, it is stated, is absent in the young.

(c) The ciliated pits are further forward, being midway between the brain and the anterior end of the body.

(d) The proboscis and its retractor muscle are much more undulating, when withdrawn into the body, than Silliman shows.

The proboscidial spine, with its groups of accessory spines, agrees very closely with the figures given by Silliman.

I can say nothing about the generative organs. For the present, then, I must leave undecided the specific name of this British Tetrastemma.

Anatomical Department, Museum, Oxford, Oct. 12.

\section{Protective Mimicry.}

Mr. Bateson's letter on "Aggressive Mimicry" (NATURE, October 20 ) recalls to my mind a curious case of protective mimicry which came under my notice last August on Dartmoor. Large patches of the heath had been burnt, a common practice on the moorlands to ensure a fresh young growth for the sheep. The whole ground was alive with a common species of orthoptera (Locustina), the small green grasshopper with short antennæ. They leapt aside at every step in the short grass and scrubby heath; upon the burnt patches they were equally numerous, but with this difference--all, without exception, were coal black on abdomen, thorax, and head, whilst the wings were of an ashen hue. So much did the colour adaptation resemble the blackened turf and heath they hopped amongst it was almost impossible to follow them with the eye ; we made many amusing attempts, but were nearly always defeated. I measured one of these burnt patches, and found it to be from thirty to forty yards square. A yard or two from this, on the untouched herbage all the Locustina were bright green. I found one specimen on the borderland in a transition state, not dull all over as I had expected, but in spots and patches of bright green and black. One enemy at least of these insects abounded on the moor, namely, the common lizard (Zootaa vivipara), for I have observed there is no food lizards will eat more greedily than grasshoppers. I have seen some that I have in captivity swallow twenty or thirty in two or three minutes, even after their usual meal of worms. They always beeame greatly excited, if one may apply so warm an expression to such cold-blooded animals, and rushed about the case when a collection of live grasshoppers were thrown to them. Certainly I was much struck by the rapid action of the power possessed by these Locustina on Dartmoor of assimilation to environment, and did not doubt but that this colour adaptation was for the purpose of protection, the eye producing by reflex action the change in the pigment cells. Rose HaIG ThOMAS.

\section{STELLAR PARALLAX.'}

$\mathrm{T}$ HE Delegates of the University Press have recently published the results of Prof. Pritchard's systematic investigations into the parallax of those stars of the second magnitude whose North declination permits the inquiry to be made with facility and advantage in these latitudes. Our first feeling on glancing over the contents of this brochure must be one of hearty congratulation to the distinguished professor that he has been permitted to see the full outcome of a protracted inquiry, conducted at a period in his life when a less energetic astronomer would have felt himself justified in withdrawing from active participation in scientific research.

I "Researches in Stellar Parallax by the aid of Photography." By Charles Pritchard, D.D., F.R.S., Savilian Professor of Astronomy in Oxford.

NO. 1200, VOL. 46]
Prof. Pritchard might well have been content to rest on the laurels he had won, and to have staked his reputation upon that career of acknowledged utility which has marked his direction of the Oxford University Observatory.

Immediately on the completion of the photometrical examination of Argelander's Uranometria, and with a zeal that admitted of no delay, Professor Pritchard busied himself with this inquiry into the parallax of stars of the second magnitude. But if the inquiry was undertaken with eagerness, and pursued with ardour and resolution, it was not characterized by hurry, or its success imperilled by incompleteness. Confident himself that photographic methods possessed the requisite accuracy to make the research successful and trustworthy, the Savilian Professor set to work to establish the reliable character of measurements made on sensitized films, and not till that confidence was demonstrated did he embark upon the larger work now under notice. These preliminary inquiries have been published in a series of papers in the proceedings of the Royal and Royal Astronomical Societies, and the confidence gradually acquired by enlarged experience induced him to proceed with the determination of the parallax of $6 \mathrm{r}$ Cygni, the results of which are published in detail in the third fasciculus of the Annals of the University Observatory. In this case he selected four stars in the immediate neighbourhood of the principal star, and sought the difference of parallax between each of the components and of the four stars of comparison. This long research may be regarded by some as a work of supererogation, inasmuch as the labours of Bessel and that of many later astronomers have satisfactorily settled the parallax of this star within very approximate limits. But if we properly understand the motives of Prof. Pritchard, his intention was not so much to seek anew the parallax of that system, as to discover with what degree of accuracy the method of photography, hither to unapplied in this direction, represented the work of others made directly in the field of the telescope. Nor was this his only view. By selecting four stars in the immediate neighbourhood of 6r Cygni and seeking the difference of parallax between these stars of comparison and each of the components of the system, he instituted a very severe inquiry as to the trustworthiness of that method, which he had imagined as capable of dealing with the delicate question of stellar parallax. The severity of the test consists in deducing the same value of the parallax (eight in all) from each set of measures, and as a matter of fact the accordance, inter se between these several determinations is as close as could have been anticipated, and likewise in satisfactory unison with the work of other astronomers.

The completeness of this inquiry and the publication of it in detail have had two happy results. In the first place, Prof. Pritchard has, in the present instance, been able to confine the printing within very narrow limits, so narrow, indeed, as possibly not to have done himself justice. The details of his process, the mutual agreement of his measures, and his method of discussion having all been fully set out in his previous work, he has not felt himself obliged to enter into these minute particulars, but has contented himself with presenting the results. This method of arrangement, no doubt suggested in the first place by economical motives, has afforded opportunity for adding a very interesting history of the processes and results that have hitherto been followed with more or less success by others, and also the exhibition in a concise form of the different values of the more trustworthy determinations, derived by previous observers. The second advantage, immediately arising from the earlier investigations, is, that an examination of those results has shown that no increase of accuracy (commensurate with the increased labour at 
least) was obtained by continuing the observations of the stars throughout the whole of the year, that is, to secure observations in all positions of the parallactic ellipse. If the measures were confined to those epochs when the parallactic displacements were greatest, and a sufficient number of observations secured at those critical times, a determination of parallax could be relied upon to within about one-thirtieth of a second of arc. This is approximately the limit of accuracy that Professor Pritchard hoped to reach, and in this selection he appears to have been guided by the conviction, that in the present condition of cosmical inquiries, to which stellar parallax bears the closest relation, it is of more importance to know within very narrow limits the parallaxes of many stars than seek with the utmost accuracy the parallax of a very few. And in this respect there can be no doubt but that Prof. Pritchard's judgment is correct. The former is the view of a philosopher; the latter that of a conscientious and painstaking observer. Guided by the broader view, the result of his work has been to enrich the data at the command of students of cosmical science by assigning the approximate distance to some thirty stars, a number which bears no inconsiderable proportion to the total number of separate determinations made by all other astronomers combined.

Prof. Pritchard's view of the history of stellar parallax is that of a scientific struggle, a continual and severe wrestle on the part of the astronomer with the inevitable inaccuracy of observation and imperfect instruments, in which sometimes one opponent, sometimes the other, has the mastery. He passes in his historic survey rapidly over those days when from various obvious causes the detection of stellar parallax was scarcely possible, moved however to admiration by, and induced to linger over, the success that attended the early observations of Molyneux in the case of $\gamma$ Draconis when discussed, a century later, by Auwers, a success that later observers have struggled to repeat ineffectually. He brings before us, but touches with a light and kindly hand, the dispute that embittered the lies of Brinkley and of Pond, but it is not difficult in reading a little between the lines to see with whom his sympathies rest. Later on in the history of the research, Henderson meets with his deserts, as a clear-sighted astronomer of distinguished ability, cautious and persevering, and one who in the struggle after accuracy obtained an undoubted measure of success. This historical introduction will we think be read with pleasure by many who may have no particular interest in this special subject of inquiry. The comments of one who has encountered and overcome many similar difficulties, and has kindly sympathy with all who have travelled along the same path, cannot but be of interest and of value, and we could have wished that this portion of the book had been considerably extended. How many astronomers are now acquainted, with any degree of adequacy, with the serious difficulties that attended the early application of the heliometer in this department of research, and with the dispute that raged long and dubiously around the names of Wichmann and of Schluter? All are willing to admit that in the hands of many competent observers-it would be invidious to mention any without naming all - the heliometer is doing splendid work, but the difficulties with which the early masters had to cope are now all but forgotten, and it is certainly wise to treasure a sympathetic remembrance for the earlier exponents of the improved and successful methods now in vogue.

The last portion of Prof. Pritchard's history is occupied with the bearing of stellar parallax on the problem of the construction of the stellar universe. He seems to have had before his mind two questions, which, long hovering in an unexpressed form, were first formally enunciated by Dr. Gill. The first question is, What are the average parallaxes of stars of the first, NO. I 2OO, vOL. 46] second, third, and fourth magnitude respectively compared with those of fainter magnitude? To this question the Savilian Professor replies very cautiously. The researches of Dr. Elkin on stars of the first magnitude point to an average parallax of $0^{\prime \prime} \cdot 089$ for stars of that class, and just as certainly Prof. Pritchard's researches point to an average parallax of $\mathrm{o}^{\prime \prime} .056$ for stars of the second magnitude. But he pertinently asks what can be understood by an average of distances (as indicated by parallaxes) in cases where the separate elements vary from actual zero to half a second, and where moreover many of the brighter members are the furthest removed from us? Notwithstanding these exceptional cases, which challenge attention, the fact remains, and it is apparently the only conclusion which can be drawn with any certainty, that the stars of the first magnitude are on the whole nearer to us than those of the second, and that these again are as a whole nearer to us than the faint stars with which they have been compared. With conclusions of this sort it would seem that astronomers will have to content themselves for some time to come.

The second question which Dr. Gill suggested or formulated was-What connection does there exist between the parallax of a star and the amount and direction of its proper motion?-or can it be proved that there is no such connection or relation? The answer given to this second query is even less satisfactory than to the former. Prof. Pritchard contents himself by exhibiting in a tabular form the parallax and the proper motion of all stars that have been successfully handled, and the only conclusion drawn or warranted, is a suggestion that there is at least quite as close a connection between the apparent proper motion of a star and its distance from us, as there is between its distance and its magnitude.

If we examine or attempt to trace any connection between the mass, the brilliancy and the distance of a star, we are baffled by the same kind of uncertainty, arising in some measure from the paucity of instances in which it is possible to make the inquiry, and we are reluctantly forced to admit that such investigations are premature. At least that would be the conclusion of an ordinary mind, but here it is that Prof. Pritchard sees his opportunity for future efforts and renewed vigour. With an energy that must be the admiration of his friends, he selects for further investigation two subjects, either of which might fully occupy the time and the hands of a younger man. He proposes in the first place to determine the parallaxes of several stars of the Pleiades, a few of the brighter as well as a few of the fainter, with the view of discovering whether the faint and the bright are indiscriminately mixed at that distance. The second subject of his proposed inquiry is not less interesting. It consists in the investigation of the distances of some of the binary systems from our sun; and from a more complete knowledge of the masses, the mutual distances, and the parallaxes of these systems, Prof. Pritchard thinks it not unlikely that many interesting and possibly unexpected associations may reasonably be anticipated, thereby affording us some further insight into the constitution and the mechanism of the Stellar Universe. We can only hope that Prof. Pritchard's health and strength may be spared to witness the completion of this programme, but in that case we are assured he would immediately sketch out for himself some new field of inquiry, and court even longer and more protracted labour.

\section{CONTRIBUTIONS TO THE STUDY OF DISINFECTION. ${ }^{1}$}

PROFESSOR J. MASCHEK, whose name is already familiar to us through his investigations on water bacteria, has brought together in pamphlet-form a large

I" Beiträge zur Theorie und Praxis der Desinfection, von Prof. J. Maschek." Im Selbstverlage des Verfassers, Leitmeritz. 